\title{
Air pollution and COVID-19: clearing the air and charting a post-pandemic course: a joint workshop report of ERS, ISEE, HEI and WHO
}

\author{
Zorana J. Andersen ${ }^{1}$, Barbara Hoffmann ${ }^{2}$, Lidia Morawska ${ }^{3}$, Martin Adams ${ }^{4}$, Eeva Furman ${ }^{5}$, \\ Arzu Yorgancioglu ${ }^{6}$, Dan Greenbaum ${ }^{7}$, Maria Neira ${ }^{8}$, Bert Brunekreef ${ }^{9}$, Francesco Forastiere ${ }^{10}$, \\ Mary B. Rice $\mathbb{C}^{11}$, François Wakenhut ${ }^{12}$, Erika Coleen ${ }^{13}$, Hanna Boogaard ${ }^{7}$, Ulrike Gehring ${ }^{9}$, Erik Melén $\mathbb{C}^{16}$, \\ Brian Ward ${ }^{17}$ and Sara De Matteis ${ }^{18,19}$
}

\begin{abstract}
${ }^{1}$ Environmental Epidemiology Group, Section of Environmental Health, Dept of Public Health, Faculty of Health and Medical Sciences, University of Copenhagen, Copenhagen, Denmark. ${ }^{2}$ Institute for Occupational, Social and Environmental Medicine, Centre for Health and Society, Medical Faculty, Heinrich-Heine-University of Düsseldorf, Düsseldorf, Germany. ${ }^{3}$ International Laboratory for Air Quality and Health (ILAQH), School of Earth and Atmospheric Sciences, Queensland University of Technology, Brisbane, Australia. ${ }^{4}$ European Environment Agency, Copenhagen, Denmark. ${ }^{5}$ Finnish Environment Institute, Helsinki, Finland. ${ }^{6}$ Celal Bayar University Medical Faculty, Dept of Pulmonology, Manisa, Turkey. ${ }^{7}$ Health Effects Institute, Boston, MA, USA. ${ }^{8}$ World Health Organization, Geneva, Switzerland. ${ }^{9}$ Institute for Risk Assessment Sciences (IRAS), Utrecht University, Utrecht, The Netherlands. ${ }^{10}$ Imperial College, London, UK. ${ }^{11}$ Division of Pulmonary, Critical Care and Sleep Medicine, Beth Israel Deaconess Medical Center, Boston, MA, USA. ${ }^{12}$ Clean Air Unit, DirectorateGeneral Environment, European Commission, Brussels, Belgium. ${ }^{13}$ Belgian Asthma and Allergy Association, Brussels, Belgium. ${ }^{16}$ Dept of Clinical Sciences and Education, Karolinska Institutet, Södersjukhuset, Stockholm, Sweden. ${ }^{17}$ European Respiratory Society, Brussels, Belgium. ${ }^{18}$ Dept of Medical Sciences and Public Health, University of Cagliari, Cagliari, Italy. ${ }^{19}$ National Heart and Lung Institute, Imperial College London, London, UK.
\end{abstract}

Corresponding author: Zorana Andersen (zorana.andersen@sund.ku.dk)

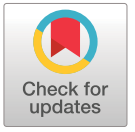

Copyright @The authors 2021.

This version is distributed under the terms of the Creative Commons Attribution Non-Commercial Licence 4.0. For commercial reproduction rights and permissions contact permissions@ersnet.org

Received: 12 April 2021 Accepted: 26 June 2021

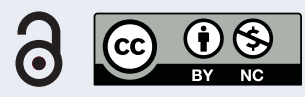

Shareable abstract (@ERSpublications)

The potential role of air pollution in the worsening of health impacts of COVID-19, and the influence of the pandemic on air pollution levels in Europe is explored. This editorial outlines the major lessons learned to chart a healthy post-pandemic course. https://bit.ly/3hmbaya

Cite this article as: Andersen ZJ, Hoffmann B, Morawska L, et al. Air pollution and COVID-19: clearing the air and charting a post-pandemic course: a joint workshop report of ERS, ISEE, HEI and WHO. Eur Respir J 2021; 58: 2101063 [DOI: 10.1183/13993003.01063-2021].

\section{Introduction}

Air pollution is now recognised by governments, international institutions and civil society as a major global public health risk factor. The health burden of air pollution is large: 509000 premature deaths every year in Europe [1] and serious aggravations of heart and lung diseases that affect millions of patients, both children and adults. The European Environmental Agency estimated that in 2018 there were 417000 premature deaths attributable to particulate matter with diameter $<2.5 \mu \mathrm{m}\left(\mathrm{PM}_{2.5}\right), 55000$ to $\mathrm{NO}_{2}$, and 20600 to $\mathrm{O}_{3}$ in Europe (table 10.1 in EEA Report 9/2020 [2]). In addition, 4805800 years of life lost could be attributed to $\mathrm{PM}_{2.5}, 623600$ to $\mathrm{NO}_{2}$, and 246700 to $\mathrm{O}_{3}$ (table 10.2 in [2]). This "silent killer" is one the most important determinants of health, surpassed only by high blood pressure, tobacco use and poor diet. The coronavirus disease 2019 (COVID-19) pandemic has raised concerns about whether air pollution can increase the severity of disease and risk of death after infection, as well as facilitate the spread of severe acute respiratory syndrome coronavirus 2 (SARS-CoV-2). Chronic lung disease patients are in the epicentre of the current crisis, as they are more vulnerable to both the adverse effects of a SARS-CoV-2 infection and air pollution exposure, as well as their possible interactions. At the same time, the lockdown measures to control the spread of COVID-19 brought historical short-term reductions in air pollution levels around the globe, and increasing general public interest and demand for clean air policies [3]. The COVID-19 pandemic, an emerging infectious disease probably caused by a spill over from animals, and its possible interactions with air pollution, is an existential reminder that we are a part of a larger ecosystem, and that human health is closely connected with the health of our environment and planet. Here we provide a short summary on the potential role of air pollution in the spread and worsening 
TABLE 1 Main highlights on air pollution and coronavirus disease 2019 (COVID-19): clearing the air and charting a post-pandemic course

Long-term exposure to outdoor air pollution can increase the risk of infection and death from COVID-19

Ambient air pollution particles do not transmit SARS-CoV-2 virus

The COVID-19 crisis highlights the close link between human and planetary health

COVID-19 lockdown measures have resulted in unprecedented short-term reductions in air pollution, showing a glimpse of what can be achieved

Bold and ambitious policies moving away from fossil fuels are needed to ensure long-term reductions in air pollution

Strict air pollution policies help tackle climate change by reducing greenhouse gases emissions

Cleaner air will provide immediate health benefits to European populations and, in the long run, ensure more healthy and resilient populations, environment and the planet

of health impacts of COVID-19, and on the influence of the pandemic on air pollution levels in Europe. Moreover, we outline the major lessons learned to chart a healthy post-pandemic course. This work summarises the key messages from a workshop that took place on 2 December, 2020, organised by the European Respiratory Society (ERS), the International Society for Environmental Epidemiology (ISEE) and the Health Effects Institute (HEI), endorsed by the World Health Organization (WHO), and hosted by the European Parliament Lung Health Group and the European Commission (table 1).

Does air pollution increase COVID-19 severity?

Ecological studies showing simple correlations between regional long-term air pollution levels and COVID-19 mortality rates have given rise to the hypothesis of increased susceptibility of populations living in areas with high air pollution towards COVID-19 [4]. However, these studies, as well as more sophisticated ecological assessments, where mean air pollution levels in an area (county, municipality, etc.) were linked to the COVID-19 mortality or case-fatality rates in that area, are inadequate for assessing the potential association between air pollution and COVID-19 [5, 6]. The major limitation of these studies is that they are based on aggregated data for a group and lack detailed information on an individual level, and that results of these types of studies can be erroneously used for inference at the individual level, leading to so-called "ecological fallacy". Statistically, a correlation tends to be larger when an association is assessed at the group level than when it is assessed at the individual level, implying that "ecological fallacy" can lead to overestimation of real effects [7]. Furthermore, results of these studies should be interpreted with caution, as many were published ahead of rigorous peer-review, and may have methodological flaws, such as lack of adjustment for social contacts and mobility, which are important drivers of the COVID-19 epidemic. For example, a US study raised headlines globally in May 2020 by showing that a small increase of $1 \mu \mathrm{g} \cdot \mathrm{m}^{-3}$ in long-term average county-level concentrations of $\mathrm{PM}_{2.5}$ was associated with a sizeable $15 \%$ increase in the county-level COVID-19 death rate [5]. Notably, this estimate was soon corrected to $8 \%$ when taking into account dynamics of the disease, in terms of the time of virus introduction in each county, demonstrating the necessity of correcting for those factors. Notably, another US study using the same data, but with more complete control for confounding and spatial autocorrelation, found no associations with $\mathrm{PM}_{2.5}$ [6]. Another reason for concern about the generalisability of these early studies conducted during the first months of the pandemic is the dynamics of the geographical differences in COVID-19 burden within the same country, where typically, higher urban COVID-19 burden compared to other areas (coinciding with higher air pollution levels in more urban areas), was reduced or diminished later on. These early studies, using very early, highly aggregated population data, have motivated calls for individual level (cohort) data with careful control for relevant confounders and underlined the importance of rigorous research on air pollution and COVID-19 [8, 9]. A single cohort study with individual-level data was based on US veterans and found a $10 \%$ increase in risk of hospitalisation among those who tested positive for COVID-19, for each $1.9 \mu \mathrm{g} \cdot \mathrm{m}^{-3}$ increase in $\mathrm{PM}_{2.5}$ [10]. Consequently, with the current lack of a substantial number of individual-level studies, attempts to quantify the fraction of global COVID-19 deaths attributed to $\mathrm{PM}_{2.5}$ [11] is premature and imprecise [12].

Nevertheless, an association of long-term exposure to air pollution with an increased COVID-19 infection risk and severity is biologically plausible [13]. Experimental studies show that particulate matter exposure can impair cell immunity and weaken host defence mechanisms, increasing susceptibility to respiratory infections [14]. This is caused by direct cellular damage, and indirectly, via oxidative stress and inflammation in the lung and systemically [15-17]. Furthermore, $\mathrm{PM}_{2.5}$ was found to cause over-expression of ACE (angiotensin-converting-enzyme)-2 receptors [18], the key target of SARS-CoV-2 
for human cell entry, thereby promoting viral entry and damage to the cell [19]. The so-called "double hit" model of air pollutants and SARS-CoV-2 interaction therefore proposes that air pollution increases susceptibility to infection and severity of disease via facilitating viral entry as well as reducing host defences [20]. Consistent with this, epidemiological studies conducted prior to the COVID-19 pandemic have linked long-term exposure to air pollution to increased risk of respiratory infections such as pneumonia [21]. Furthermore, it is well known that air pollution increases the risk of a number of chronic (respiratory, cardiometabolic) diseases, the same ones reported as the comorbidities increasing the risk of being hospitalised or dying from COVID-19 [22].

How did COVID-19 lockdown affect air pollution levels in Europe?

Lockdown measures to control the COVID-19 pandemic in Europe in 2020 have resulted in significant reductions in air pollutant emissions and concentrations within days and weeks, though with notable differences between pollutants, countries and cities [2]. The largest decreases in monthly averages of up to $70 \%$ in $\mathrm{NO}_{2}$, compared with expected concentrations in the absence of lockdown measures, were observed at traffic monitoring stations in Spain and Italy, while reductions in background $\mathrm{NO}_{2}$ concentrations for selected countries ranged from an average $61 \%$ in Spain to $20 \%$ in Czech Republic. In some cities, $\mathrm{NO}_{2}$ levels remained relatively low even after lockdown measures were lifted (Milan, Italy), while in others (Athens, Greece) they rapidly returned to "normal” [2]. For $\mathrm{PM}_{2.5}$, decreases in background concentrations ranged from 30\% in Spain to 9\% in the Czech Republic, compared to expected levels. Reductions in $\mathrm{PM}_{2.5}$ levels were smaller and less consistent than those for $\mathrm{NO}_{2}$, owing to the generally more varied sources of $\mathrm{PM}_{2.5}$, especially in urban areas, including the combustion of fossil fuel for heating, industrial activities, long-range transportation of particles, road traffic and secondary particle formation. Importantly, these reductions were largely short term, with levels rebounding as economic activity increased again.

\section{What is the role of ambient air pollution in transmission of COVID-19?}

There has been speculation that particles in the air may serve as a carrier of SARS-CoV-2 virus-laden respiratory particles, thereby enhancing transmission in areas with higher levels of particulate matter pollution. There have been several studies published linking ambient air pollution $\left(\mathrm{PM}_{2.5}\right.$ or $\mathrm{NO}_{2}$ concentrations) and the number of infection cases based on simple correlation analysis. However, without considering other critical factors driving the pandemic, and in particular severely limited human interactions during lockdowns (for the purpose of halting the spared of the pandemic), the relationships uncovered are likely proxies for other factors, in particular reduction in traffic and industrial activities, hence reduction in the emissions to the air, and in turn concentrations of pollutants in the cites where lockdowns where implemented. Most outdoor air particles are small, within the lower submicrometre size range [23, 24]. A "naked" SARS-CoV-2 virus measures approximately $0.12 \mu \mathrm{m}$, however, virus-laden respiratory particles also contain water, mucus and salts [25] and measure up to a few micrometres [26, 27]. Thus, since an aerosolised virus in the air is not "naked", the majority of particles in urban air, which are small [28] cannot be carriers of such bigger, virus-laden particles. Furthermore, the interaction between same size particulate matter and SARS-CoV-2 virus particles is very slow, because their respective concentrations in outdoor air are low, in contrast to indoor air, where the majority of human exposure to SARS-CoV-2 virus occurs. Hence, ambient air pollution particles likely do not play a role in the transmission of SARS-CoV-2.

What did COVID-19 teach us about planetary health?

The world today is highly interconnected with intensive global flows of people, natural resources and pollution between all parts of the world. This causes major destruction in wildlife populations and ecosystems and increases contact between human populations and wildlife reservoirs of potentially pathogenic bacteria and viruses. Ecosystem destruction leads to species loss and population decline. The disturbed system now starts to favour species with high reproductive rates and short life cycles. They form highly dense populations, typically also highly conductive and prone to transmit diseases. When natural food webs are disturbed, the resource use behaviour in higher trophic levels changes, making them prone to high mutation rate pathogens, such as SARS-CoV-2 type RNA viruses. Reaching a new cyclic balance, e.g. for COVID-19, may take at least two years [29]. The unprecedented scale at which animals are raised for food production nowadays also increases the risks of infectious disease spill over from animal to human populations. The COVID-19 crisis highlights the link between human health and healthy ecosystems, underlining the need to take a more comprehensive and planetary approach to health. The Helsinki Declaration of Planetary Health [30] calls upon impact-oriented actions in policies much beyond the health sector, both in the long and short term, and emphasises that both the health of human civilisation and the state of natural systems on which it depends, must become the driver of all policies. This requires knowledge about emergence to spread, health impact, socio-political response and recovery plan from multidisciplinary research. 
The tragedy of COVID-19 exposes our vulnerability as a global society and our dependence on healthy ecosystems. The pandemic has made us reflect on how we can repair the systemic failure that brought us here, and how can we restore a healthy human-nature relationship to best protect ourselves and future generations from the next man-made crisis, whether it is caused by infectious agents, climate change or pollution. The "WHO Manifesto for a Healthy Recovery from COVID-19” [31] provides six prescriptions for a green recovery, including: 1) recovering relationship with our nature through biodiversity; 2) providing access to safe water and basic hygiene; 3) accelerating transition to renewable energy and stopping fossil fuel combustion; 4) promoting sustainable food production, consumption and waste management; 5) building healthy and sustainable cities with health in focus of urban planning; and 6) making sure that stimulus packages for economic recovery are not funding the fossil fuel-based economy. Tackling causes of air pollution is intricately connected with some of these prescriptions, and is an urgently needed investment that will reduce susceptibly and mortality from COVID-19 and other respiratory pathogens, while also reducing the 6.7 million premature deaths due to air pollution annually globally.

Even before it emerged that air pollution may be a risk factor for more severe illness from COVID-19, the pandemic alerted us to a number of issues: 1) the importance of lung health, and our vulnerability to infectious respiratory pathogens that can spread rapidly in our highly mobile society; 2) the massive disparities in social determinants of health that are clearly visible around the world; and 3) society's remarkable willingness to make severe personal and economic sacrifices for the sake of health, especially when decision-making is transparent and evidence-based. In the joint statement "Bounce Back Better: Sustainable Strategies for a Healthy Recovery from the Pandemic" [32] from the ERS, American Thoracic Society and ISEE, professional societies dedicated to promoting respiratory and environmental health, the COVID-19 pandemic is viewed as a historic opportunity to rethink societal priorities towards clean energy and sustainability in all areas. Similarly, "COVID-19 Pandemic: A Wake-Up Call for Clean Air" calls for that cleaning up of air as a necessary ingredient of post COVID-19 recovery, for improving respiratory health and equality worldwide [33].

The European Commission adopted a European Green Deal (EGD) in December 2019, just ahead of the COVID-19 crisis, as a strategy to be the first climate neutral (reducing greenhouse gas emissions as much as possible and compensating for any remaining emission) continent in the world. An integral part of the EGD is "A Zero Pollution Ambition", at the core of which is clean air. Within the EGD, the European Commission has proposed to revise the EU Air Quality Standards to align them more closely with the WHO Air Quality Guideline recommendations [34], of which a new update will be published in 2021. It will be important that the latest scientific evidence on the health effects of air pollution is presented and considered in the legislative discussions. The impact of COVID-19 lockdowns on air quality was notable, but came at a significant short-term economic disruption. Seeing that we can achieve drastic air pollution reductions, we need to build those into structural changes as part of a long-term green recovery strategy, including the key principles of “do no harm”, zero pollution and clean air objectives.

\section{Conclusion}

Air pollution can increase the severity and risk of death from COVID-19 infection, by compromising the individual immune system's ability to fight infections and by increasing the risk of predisposing chronic diseases. We need carefully designed studies at the individual level, preferably from several countries using the same protocols and design, in order to quantify the burden of COVID-19 due to air pollution. The COVID-19 pandemic has painfully demonstrated the close interconnectedness of a fossil fuel-based economy, climate change, air pollution and emerging infectious diseases, and provides compelling additional motivation for stricter air pollution regulation, as an integral and imperative part of post pandemic policies, ensuring more healthy and resilient populations. The unprecedented decreases in air pollution around Europe during the COVID-19 lockdown showed an example of what can be achieved. As air pollution is increasing again back to pre-pandemic levels, we need bold policies and structural changes in our cities, transportation, industry, agriculture and energy systems to ensure long-term reductions in air pollution and greenhouse gases, moving away from fossil fuels. As cleaner air policies will provide immediate substantial health benefits to European citizens, their co-benefits in tackling climate change crises make them central to ensuring more healthy and resilient populations, environment and the planet.

The opinions expressed in this manuscript are those of the authors and should not be considered to represent an official position of the European Commission.

Conflict of interest: Z.J. Andersen has nothing to disclose. B. Hoffmann has nothing to disclose. L. Morawska has nothing to disclose. M. Adams has nothing to disclose. E. Furman has nothing to disclose. A. Yorgancioglu has 
nothing to disclose. D. Greenbaum has nothing to disclose. M. Neira has nothing to disclose. B. Brunekreef has nothing to disclose. F. Forastiere reports personal fees for consultancy from Health Effects Institute, during the conduct of the study; personal fees for advisory board work from Health Effects Institute, outside the submitted work. M.B. Rice has nothing to disclose. F. Wakenhut has nothing to disclose. E. Coleen has nothing to disclose. H. Boogaard has nothing to disclose. U. Gehring has nothing to disclose. E. Melén has nothing to disclose. B. Ward is an employee of the European Respiratory Society. S. De Matteis has nothing to disclose.

\section{References}

1 World Health Organization. Burden of Disease from Ambient Air Pollution for 2016. Geneva, World Health Organization, 2018.

2 European Environment Agency. Air Quality in Europe - 2020 report. EEA Report No 9/2020. Luxembourg, Publications Office of the European Union, 2020.

3 To T, Viegi G, Cruz A, et al. A global respiratory perspective on the COVID-19 pandemic: commentary and action proposals. Eur Respir J 2020; 56: 2001704.

4 Fattorini D, Regoli F. Role of the chronic air pollution levels in the Covid-19 outbreak risk in Italy. Environ Pollut 2020; 264: 114732.

5 Wu X, Nethery RC, Sabath BM, et al. Exposure to air pollution and COVID-19 mortality in the United States: a nationwide cross-sectional study. medRxiv 2020; preprint [https://doi.org/10.1101/2020.04.05.20054502].

6 Liang D, Shi L, Zhao J, et al. Urban air pollution may enhance COVID-19 case-fatality and mortality rates in the United States. Innovation (New York, NY) 2020; 1: 100047.

7 Hsieh JJ. 'Ecological fallacy'. Encyclopedia Britannica. www.britannica.com/science/ecological-fallacy Date last updated: 4 September 2017

8 Villeneuve PJ, Goldberg MS. Methodological considerations for epidemiological studies of air pollution and the SARS and COVID-19 coronavirus outbreaks. Environ Health Perspect 2020; 128: 95001.

9 Heederik DJJ, Smit LAM, Vermeulen RCH. Go slow to go fast: a plea for sustained scientific rigour in air pollution research during the COVID-19 pandemic. Eur Respir J 2020; 56: 2001361.

10 Bowe B, Xie Y, Gibson AK, et al. Ambient fine particulate matter air pollution and the risk of hospitalization among COVID-19 positive individuals: Cohort study. Environ Int 2021; 154: 106564.

11 Pozzer A, Dominici F, Haines A, et al. Regional and global contributions of air pollution to risk of death from COVID-19. Cardiovasc Res 2020; 116: 2247-2253.

12 Brunekreef B, Downward G, Forastiere F, et al. Air pollution and COVID-19. Including elements of air pollution in rural areas, indoor air pollution and vulnerability and resilience aspects of our society against respiratory disease, social inequality stemming from air pollution, study for the committee on Environment, Public Health and Food Safety, Policy Department for Economic, Scientific and Quality of Life Policies. Luxembourg, European Parliament, 2021.

13 Bourdrel T, Annesi-Maesano I, Alahmad B, et al. The impact of outdoor air pollution on COVID-19: a review of evidence from in vitro, animal, and human studies. Eur Respir Rev 2021; 30: 200242.

14 Ciencewicki J, Jaspers I. Air pollution and respiratory viral infection. Inhal Toxicol 2007; 19: 1135-1146.

15 Schraufnagel DE, Balmes JR, Cowl CT, et al. Air pollution and noncommunicable diseases: a review by the forum of international respiratory societies' environmental committee, part 1: the damaging effects of air pollution. Chest 2019; 155: 409-416.

16 Schraufnagel DE, Balmes JR, Cowl CT, et al. Air pollution and noncommunicable diseases: a review by the forum of international respiratory societies' environmental committee, part 2: air pollution and organ systems. Chest 2019; 155: 417-426.

17 Hajat A, Allison M, Diez-Roux AV, et al. Long-term exposure to air pollution and markers of inflammation, coagulation, and endothelial activation: a repeat-measures analysis in the Multi-Ethnic Study of Atherosclerosis (MESA). Epidemiology (Cambridge Mass) 2015; 26: 310-320.

18 Borro M, Di Girolamo P, Gentile G, et al. Evidence-based considerations exploring relations between SARS-CoV-2 pandemic and air pollution: involvement of PM2.5-mediated up-regulation of the viral receptor ACE-2. Int J Environ Res Public Health 2020; 17: 5573.

19 Gupta A, Madhavan MV, Sehgal K, et al. Extrapulmonary manifestations of COVID-19. Nat Med 2020; 26: 1017-1032.

20 Frontera A, Cianfanelli L, Vlachos K, et al. Severe air pollution links to higher mortality in COVID-19 patients: the 'double-hit' hypothesis. J Infect 2020; 81: 255-259.

21 Grigg J. Air pollution and respiratory infection: an emerging and troubling association. Am J Respir Crit Care Med 2018; 198: 700-701.

22 Guan WJ, Liang WH, Zhao Y, et al. Comorbidity and its impact on 1590 patients with COVID-19 in China: a nationwide analysis. Eur Respir J 2020; 55: 2000547.

23 de Jesus AL, Thompson H, Knibbs LD, et al. Two decades of trends in urban particulate matter concentrations across Australia. Environ Res 2020; 190: 110021. 
24 Beddows DCS, Dall'Osto M, Harrison RM, et al. Variations in tropospheric submicron particle size distributions across the European continent 2008-2009. Atmos Chem Phys 2014; 14: 4327-4348.

25 Morawska L, Johnson GR, Ristovski ZD, et al. Size distribution and sites of origin of droplets expelled from the human respiratory tract during expiratory activities. J Aerosol Sci 2009; 40: 256-269.

26 Santarpia JL, Herrera VL, Rivera DN, et al. The infectious nature of patient-generated SARS-CoV-2 aerosol. medRxiv 2020; preprint [https://doi.org/10.1101/2020.07.13.20041632].

27 Ma J, Qi X, Chen H, et al. COVID-19 patients in earlier stages exhaled millions of SARS-CoV-2 per hour. Clin Infect Dis 2020; 72: e652-e654.

28 de Jesus AL, Rahman MM, Mazaheri M, et al. Ultrafine particles and $\mathrm{PM}_{2.5}$ in the air of cities around the world: Are they representative of each other? Environ Int 2019; 129: 118-135.

29 Kissler SM, Tedijanto C, Goldstein E, et al. Projecting the transmission dynamics of SARS-CoV-2 through the postpandemic period. Science (New York, NY) 2020; 368: 860-868.

30 Halonen JI, Erhola M, Furman E, et al. The Helsinki Declaration 2020: Europe that protects. Lancet Planet Health 2020; 4: e503-e505.

31 World Health Organization. WHO Manifesto for a Healthy Recovery from COVID-19. https://www.who.int/ news-room/feature-stories/detail/who-manifesto-for-a-healthy-recovery-from-covid-19 Date last updated: 26 May 2020.

32 European Respiratory Society. Bounce Back Better: Sustainable Strategies for a Healthy Recovery from the Pandemic: official statement by American Thoracic Society (ATS), European Respiratory Society (ERS) and International Society for Environmental Epidemiology (ISEE). https://www.ersnet.org/news-and-features/ news/bounce-back-better-sustainable-strategies-for-a-healthy-recovery-from-the-pandemic/

33 Mein SA, Annesi-Maesano I, Rice MB. COVID-19 pandemic: a wake-up call for clean air. Ann Am Thorac Soc 2021; in press [https://doi.org/10.1513/AnnalsATS.202012-1542VP].

34 World Health Organization. Air Quality Guidelines: Global Update 2005: Particulate Matter, Ozone, Nitrogen Dioxide, and Sulfur Dioxide. Copenhagen, WHO Regional Office for Europe, 2006. 